\title{
PENGARUH IMPLEMENTASI MODEL PEMBELAJARAN INKUIRI BASED LEARNING PADA PEMBELAJARAN BIOLOGI TERHADAP KINERJA DAN HASIL BELAJAR SISWA
}

\author{
Sukaryanto \\ SMA Negeri 2 Bantaeng \\ antotawang@gmail.com
}

\begin{abstract}
ABSTRAK
Penelitian ini bertujuan untuk mengkaji Pengaruh Implementasi Model Inkuiri Based Learning (IBL) pada pembelajaran biologi terhadap kinerja dan hasil belajar siswa. Penelitian ini dilakukan di SMA Negeri 2 Bantaeng Semester 1 Tahun Pelajaran 2019/2020, sejak tanggal 4 September 2019 hingga 18 September 2019. Materi yang diberikan pada saat pengamatan adalah Bioteknologi konvensional (Fermentasi). Subjek penelitian adalah siswa kelas XII IPA4 SMA Negeri 2 Bantaeng dengan jumlah siswa 32 orang. Hasil analisis deskriptif menunjukkan bahwa Implementasi Model Inkuiri Based Learning (IBL) rata-rata kinerja siswa 78.52\% yang berarti siswa dapat mengikuti pembelajaran Inkuiri Based Learning dengan baik, rata-rata hasil belajar siswa 70.88\% atau masuk dalam kategori tinggi, dan peningkatan hasil belajar berdasarkan indeks Gain ternormalisasi memiliki rata-rata 0,59 termasuk kategori sedang. Kesimpulan dari penelitian ini bahwa Implementasi model pembelajaran Inkuiri Based Learning (IBL) berpengaruh pada kinerja siswa dan hasil belajar siswa.
\end{abstract}

Kata Kunci: Pembelajaran Inkuiri Based Learning (IBL), Kinerja, Hasil Belajar

\begin{abstract}
This study aims to examine the effect of the Implementation of Inquiry Based Learning Model (IBL) on biology learning on student performance and learning outcomes. This research was conducted at SMA Negeri 2 Bantaeng Semester 1 in 2019/2020 Academic Year, from 4 September 2019 to 18 September 2019. The material given at the time of observation was conventional Biotechnology (Fermentation). The research subjects were students of class XII IPA4 of SMA Negeri 2 Bantaeng with 32 students. Descriptive analysis results show that the Implementation of Inquiry Based Learning Model (IBL) has an average student performance of $78.52 \%$ which means students can participate in Inquiry Based learning well, the average student learning outcomes of $70.88 \%$ or included in the high category, and increased learning outcomes based on the normalized Gain index has an average of 0.59 including the medium category. The conclusion of this study is that the implementation of Inquiry Based Learning (IBL) learning model influences student performance and student learning outcomes. Keywords: Inquiry-Based Learning (IBL), Performance, Learning Outcomes
\end{abstract}

\section{PENDAHULUAN}

Potensi untuk menyelidiki dan menemukan sesuatu merupakan kemampuan yang dimiliki setiap manusia, namun sering terhambat oleh lingkungan. Pembelajaran Biologi hendaknya mengembangkan potensi tersebut dan pembelajaran tidak boleh hanya terfokus pada aspek produk IPA, melainkan juga aspek proses IPA. Tujuan pembelajaran Biologi tidak hanya agar siswa mengingat fakta, memahami dan mengaplikasikan konsep, hukum dan teori Biologi, melainkan juga mengembangkan kemampuan mengobservasi, memprediksi, merancang serta melaksanakan penyelidikan, mengumpulkan data, menganalisis dan menginterpretasi data, menarik generalisasi serta membuat eksplanasi terhadap fenomena yang ditemukan. Pembelajaran hendaknya mempersiapkan generasi penerus menjadi generasi yang memiliki kemampuan kecakapan. Setidaknya ada empat hal yang harus dimiliki oleh generasi abad 21 yaitu: ways of thingking, ways of working, tools for working and dan skills for living in the word, sehingga seorang guru harus mendesain pembelajaran yang akan menghantarkan siswa memenuhi kebutuhan abad 21. Pembelajaran abad ke-21 yang berpusat pada siswa berbeda dengan pembelajaran tradisional yang berpusat pada guru, dalam arti bahwa keduanya memiliki pendekatan yang berbeda terhadap isi, pembelajaran, lungkungan ruang kelas, penilaian dan teknologi. Seorang pendidik harus memiliki kemampuan dalam mengatur dan mendesai pembelajaran agar siswa memiliki kemampuan kecakapan abad 21. Oleh sebab itu, diperlukan variasi metode pembelajaran yang dapat meningkatkan kinerja dan hasil belajar siswa dengan cara menjadikan siswa lebih aktif dalam proses belajar mengajar. Nilai hasil belajar biologi siswa di kelas XII IPA SMA Negeri 2 Bantaeng masih berkisar pada rata-rata 50 hingga 55 hal ini mungkin disebabkan karna pembelajaran masih berpusat pada guru dan tidak merangsang siswa untuk lebih aktif dalam pembelajaran. Model pembelajaran yang diterapkan guru merupakan salah satu faktor penting yang mempengaruhi hasil pembelajaran, termasuk pembelajaran biologi di kelas XII IPA SMA Negeri 2 Bantaeng, pembelajaran tidak akan efektif apabila guru tidak mampu menerapkan model pembelajaran yang tepat di kelas. Oleh karena itu, upaya peningkatan kualitas pembelajaran harus meliputi penggunaan model pembelajaran oleh guru 
agar siswa lebih aktif dalam belajar sehingga nilai hasil belajar siswa akan menjadi baik. Wenning (2005a, 2010) memperkenalkan Model Tingkat Penyelidikan untuk pengajaran sains dan kemudian menjelaskan urutan pembelajaran terkait secara sistematis menangani berbagai level of inquiry: discovery learning, interactive demonstrations, inquiry lessons, inquiry labs, and hypothetical inquiry (disebut juga inquiry spectrum), guru akan membantu peserta didik mengembangkan yang lebih luas. Berbagai keterampilan proses intelektual dan ilmiah. Aktivitas pembelajaran Level of Inquiry diuaraikan sebagai berikut:

1. Discovery Learning: menggunakan refleksi sebagai kunci untuk memahami konsep. Guru memperkenalkan sebuah pengalaman sedemikian rupa untuk meningkatkan relevansi atau maknanya, menggunakan serangkaian pertanyaan selama atau setelah pengalaman untuk membimbing peserta didik mencapai kesimpulan tertentu, dan memberi pertanyaan kepada peserta didik untuk mendiskusikan langsung yang berfokus pada masalah atau kontradiksi yang nyata. Dengan menggunakan penalaran induktif, peserta didik membangun hubungan atau prinsip sederhana berdasarkan hasil pengamatan yang dipandu guru.

2. Interactive Demonstration: umumnya terdiri dari seorang guru yang memanipulasi (mendemonstrasikan) peralatan dan kemudian mengajukan pertanyaan menyelidik tentang apa yang akan terjadi (prediksi) atau bagaimana sesuatu yang mungkin terjadi (penjelasan). Guru bertugas melakukan demonstrasi, mengembangkan dan mengajukan pertanyaan menyelidik, memunculkan tanggapan, meminta penjelasan lebih lanjut, dan membantu peserta didik mencapai kesimpulan berdasarkan bukti. Guru akan mendapatkan permasalahan yang muncul dari peserta didik. Guru memodelkan prosedur ilmiah yang sesuai pada tingkat yang paling mendasar, sehingga membantu peserta didik belajar secara implisit mengenai proses penyelidikan.

3. Inquiry Lesson: serupa dengan demonstrasi interaktif. Namun, ada beberapa perbedaan penting. Dalam Inquiry Lesson, penekanan secara halus beralih kebentuk percobaan ilmiah yang lebih kompleks. Guru masih berperan memberikan panduan, fasilitator, dan menggugah pertanyaan. Bimbingan diberikan secara tidak langsung dengan menggunakan strategi tanya jawab yang tepat. Guru memfasilitasi peserta didik untuk merencanakan percobaan sendiri, mengidentifikasi dan mengendalikan variabel. Guru secara eksplisit dengan memberikan panduan tentang saintifik proses melalui pertanyaan pembimbing. Proses pembelajaran pada level ini mengajak peserta didik "berpikir keras" (think aloud). Pendekatan ini akan lebih membantu peserta didik memahami proses inkuri. Inquiry Lesson ini penting untuk menjembatani kesenjangan antara demonstrasi interaktif dan Inquiry Labs.

4. Inquiry Labs: Pendekatan Inquiry Lab melibatkan aktivitas peserta didik sebagai berikut: (a) Didorong oleh pertanyaan yang membutuhkan keterlibatan intelektual berkelanjutan dengan menggunakan kemampuan berpikir tingkat tinggi untuk pemikiran independen; (b) Fokuskan kegiatan peserta didik dalam pengumpulan dan data untuk menemukan konsep, prinsip, atau hukum baru yang bergerak dari konkret menjadi abstrak; (c) Meminta peserta didik untuk membuat desain eksperimental mereka sendiri; mewajibkan peserta didik untuk mengidentifikasi, membedakan, dan mengendalikan variabel-variabel penting dan dependen; dan mendorong peserta didik memiliki keterampilan dan kemampuan saintifik inkuiri; (d) Biasanya memungkinkan peserta didik belajar dari kesalahan prosedur; memberikan waktu dan kesempatan bagi peserta didik untuk membuat dan memperbaiki kesalahannya; (e) Menggunakan prosedur yang jauh lebih konsisten dengan praktik ilmiah otentik;

5. Real-world Applications: peserta didik menerapkan apa yang telah mereka pelajari melalui pengalaman ke situasi baru. Kegiatan ini mengarahkan peserta didik bagaimana sebenarnya para ilmuwan dalam memecahkan masalah.

6. Hypothetical Inquiry: Pada level ini memberikan kesempatan kepada peserta didik untuk mengajukan hipotesis dan pengujian. Hypothetical Inquiry berhubungan dengan memberikan dan menguji penjelasan (biasanya "bagaimana", bukan "mengapa"), untuk menjelaskan hukum atau pengamatan tertentu.

Keuntungan pembelajaran dengan Level of inquiry (LOI) adalah: 1) urutan pembelajaran LOI memberikan struktur pembelajaran peserta didik yang berorientasi pada potensi peserta didik, 2) Guru dapat dengan lebih cepat merencanakan serangkaian pelajaran yang berorientasi pada penyelidikan yang koheren, 3) Peserta didik mengalami semua fase penyelidikan yang bergerak dari dasar sampai pada tingkat tinggi, 4) Peserta didik dapat memahami sains sebagai produk dan proses.

Karena harapan kami memperbaiki keadaan tersebut, maka kami memilih dan mengamati pengaruh implementasi model pembelajaran Inkuiri Based Learning (IBL) terhadap kinerja dan hasil belajar siswa.

\section{METODE PENELITIAN}

Penelitian Pengaruh Implementasi Model Pembelajaran Inkuiri Based Learning (IBL) pada pembelajaran biologi terhadap kinerja dan hasil belajar siswa ini dilakukan di SMA Negeri 2 Bantaeng pada tanggal 4 - 18 September 2019. Pengamatan pengaruh implementasi dilakukan pada kelas XII (Duabelas) IPA4 Tahun Ajaran 2019/2020 dengan jumlah siswa 32 orang. Materi yang diberikan pada saat pengamatan adalah tentang Bioteknologi konvensional (Fermentasi). Materi ini sebenarnya diberikan pada semester genap, tetapi karena kebutuhan implementasi model maka pembelajaran pada materi tersebut diajukan. Kompetensi dasar yang dipilih untuk 
menerapkan kegiatan pembelajaran biologi berbasis inkuiri adalah: 3.10 Menganalisis prinsip-prinsip Bioteknologi dan penerapannya sebagai upaya peningkatan kesejahteraan manusia; 4.10 Menyajikan laporan hasil percobaan penerapan prinsip-prinsip Bioteknologi konvensional berdasarkan scientific method, dengan indikator pencapaian kompetensi: 1) Menjelaskan konsep respirasi anaerob/fermentasi, 2) Menjelaskan proses respirasi anaerob/fermentasi, 3) Menjelaskan produk yang dihasilkan proses respirasi anaerob/fermentasi, 4) Mendemonstrasikan 1 percobaan pengamatan fermentasi, 5) Menjelaskan variabel dalam pengamatan, 6) Merancang eksperimen pengamatan fermentasi, 7) Menentukan variabel eksperimen dan hipotesis, 8) Menemukan hubungan variable yang dimanipulasi dengan variable terikat pada eksperimen yang dilakukan, 9) Menjelaskan faktor yang memepengaruhi proses fermentasi, 10) Mendiskusikan faktor-faktor lain yang mempengaruhi proses fermentasi, 11) Menjelaskan penerapan proses fermentasi dalam kehidupan nyata, 12) Membuat hipotesis dalam mengaplikasikan proses fermentasi pada kondisi yang lain.

Sebelum melakukan kegiatan pembelajaran biologi berbasis inkuiri, dilakukan penyusunan RPP konsep bioteknologi konvensional (fermentasi), kemudian diajukan ke PPPPTK IPA untuk diperiksa dan dilakukan perbaikan hingga disetujui. Kemudian dilakukan penyusunan soal berdasarkan indikator pencapaian. Observasi kinerja siswa mengunakan Instrumen yang merupakan instrument terstandar yang bersumber dari PPPPTK IPA. RPP, soal-soal test dan lembar observasi ini dapat dilihat pada lampiran.

Pelaksanakan pembelajaran dilakukan dalam 5 kali pertemuan, dengan pembagian sebagai berikut: 1) pada pertemuan pertama 30 menit untuk pretes dan 60 menit kegiatan pembelajaran biologi berbasis inkuiri, 2) 3 kali pertemuan untuk menerapkan kegiatan pembelajaran biologi berbasis inkuiri dan 3) 1 kali pertemuan untuk postes. Pada saat pembelajaran berlangsung dilakukan observasi kinerja siswa. Adapun langkah-langkah observasi kinerja dan hasil belajar kognitif siswa adalah sebagai berikut:

1. Observasi kinerja siswa dan analisis data yang mengikuti pembelajaran Biologi berbasis inkuiri. Observasi kinerja siswa yang mengikuti pembelajaran biologi berbasis inkuiri, diobservasi menggunakan instrument terstandar yang bersumber dari P4TK IPA. Observasi dilaksanakan saat siswa mengikuti pembelajaran biologi berbasis inkuiri. Observasi kinerja siswa terdiri dari pengamatan: a) Siswa menggunakan penalaran induktif untuk menghasilkan konsep/prinsip/hubungan berdasarkan pengamatan langsung dan/atau penggunaan data yang diberikan oleh guru. b) Siswa menggunakan penalaran induktif untuk menghubungkan variabel bebas dan terikat untuk menetapkan hukum empiris berdasarkan bukti yang dikumpulkan dari eksperimen. c) Siswa mengembangkan dan menguji hipotesis, membuat keputusan, memberikan penjelasan dan/atau mempertahankan kesimpulan berdasarkan bukti. d) Siswa menggunakan penalaran deduktif untuk membuat prediksi spesifik berdasarkan prinsip umum atau hukum, mengembangkan dan menguji hipotesis sebagai penjelasan tentatif untuk fenomena dan panduan untuk pengamatan lebih lanjut dan/atau eksperimen. Rentang kemampuan siswa mengikuti pembelajaran Inkuiri diinterpretasikan dari hasil analisis deskritif dengan kategori pada Tabel 1

Tabel 1. Rentang kemampuan siswa mengikuti pembelajaran Inkuiri

\begin{tabular}{|c|c|l|}
\hline $\begin{array}{c}\text { Kemam } \\
\text { puan }\end{array}$ & $\begin{array}{c}\text { Rentang } \\
\text { Nilai }\end{array}$ & \multicolumn{1}{|c|}{ Interpretasi } \\
\hline $\begin{array}{c}\text { Amat } \\
\text { Baik }\end{array}$ & $91-100$ & $\begin{array}{l}\text { siswa dapat mengikuti } \\
\text { pembelajaran inkuiri dengan } \\
\text { amat baik }\end{array}$ \\
\hline Baik & $76-90$ & $\begin{array}{l}\text { siswa dapat mengikuti } \\
\text { pembelajaran inkuiri dengan } \\
\text { baik mengikuti }\end{array}$ \\
\hline Cukup & $61-75$ & $\begin{array}{l}\text { siswa dapat dengan } \\
\text { pembelajaran inkuiri dengat } \\
\text { cukup baik kurang }\end{array}$ \\
\hline Sedang & $51-60$ & $\begin{array}{l}\text { siswa pembelajaran } \\
\text { mengikuti mat } \\
\text { inkuiri }\end{array}$ \\
\hline Kurang & $\leq 50$ & $\begin{array}{l}\text { siswa tidak dapat mengikuti } \\
\text { pembelajaran inkuiri }\end{array}$ \\
\hline
\end{tabular}

Sumber: PPPPTK IPA Rentang kemampuan siswa mengikuti pembelajaran Inkuiri (2019)

Langkah-langkah analisis data hasil belajar kognitif siswa: Instrumen soal tes digunakan sebagai instrumen utama pengumpulan data tentang pemahaman konsep siswa. Soal yang diberikan berjumlah 25 butir soal pilihan ganda yang disusun berdasarkan indikator pencapaian. Pengerjaan soal ini dilakukan siswa sebelum dan sesudah perlakuan diberikan sebagai data pretest dan postest. Soal test dapat dilihat pada lampiran. Langkah-langkah analisis data hasil belajar kognitif siswa adalah: 1) Menghitung jumlah skor siswa, 2) Membagi jumlah skor perolehan siswa dengan jumlah skor maksimal. 3) Menghitung skor hasil belajar kognitif yang dinyatakan dengan rumus:

Skor hasil belajar kognitif $=$

$\frac{\text { Jumlah skor perolehan siswa }}{\text { skor maksimal }} X 100$

Tabel 2. Kriteria hasil belajar kognitif siswa

\begin{tabular}{|c|l|}
\hline Nilai & \multicolumn{1}{|c|}{ Kategori } \\
\hline $85-100$ & Tinggi Sekali \\
\hline $65-84$ & Tinggi \\
\hline $55-64$ & Cukup \\
\hline $35-54$ & Rendah \\
\hline $0-34$ & Rendah Sekali \\
\hline
\end{tabular}

Sumber: Departemen Pendidikan Nasional (2008)

c. Anaisis Gain Ternormalisasi: Menurut Meltzer (2002), untuk mengukur peningkatan dari pretest ke posttest maka digunakan Gain ternormaisasi. Anaisis gain ternormalisasi digunakan untuk mengetahui kriteria normaisasi gain yang 
dihasilkan. Semakin besar niai $N$ Gain yang diperoleh siswa, semakin besar pula perubahan yang telah dialami oleh siswa. Berikut ini adalah rumus gain ternormalisasi dan ketegori $N$ Gain dan kategori peningktan berdasarkan indeks Gain ternormalisasi disajikan dalam Tabel 3

$$
\left\langle\mathrm{g}>=\frac{\text { skor postest }- \text { skor pretest }}{\text { skor maksimum-skor pretest }}\right.
$$

Tabel 3. Kategori peningktan berdasarkan indeks Gain ternormalisasi

\begin{tabular}{|c|c|}
\hline Indeks Gain & Kategori \\
\hline $0 \leq \mathrm{N}<0,3$ & Rendah \\
\hline $0,3 \leq \mathrm{N}<0,7$ & Sedang \\
\hline $0,7 \leq \mathrm{N} \leq 1,0$ & Tinggi \\
\hline
\end{tabular}

Sumber: Hake (1999)

\section{PEMBAHASAN}

Data Kinerja siswa kelas XII IPA4 SMA Negeri 2 Bantaeng, diperoleh melalui observasi yang dilakukan oleh dua orang guru pengamat. Observasi kinerja siswa didasarkan pada perilaku yang nampak pada siswa selama proses pembelajaran.

Tabel 4. Observasi Kinerja siswa

\begin{tabular}{|c|c|c|c|}
\hline $\begin{array}{c}\text { Kemam } \\
\text { puan }\end{array}$ & $\begin{array}{c}\text { Rentan } \\
\text { g Nilai }\end{array}$ & Interpretasi & Frekuer \\
\hline $\begin{array}{l}\text { Amat } \\
\text { Baik }\end{array}$ & $91-100$ & $\begin{array}{l}\text { siswa dapat } \\
\text { mengikuti } \\
\text { pembelajaran inkuiri } \\
\text { dengan amat baik }\end{array}$ & 5 \\
\hline Baik & $76-90$ & $\begin{array}{ll}\text { siswa } & \text { dapat } \\
\text { mengikuti } & \\
\text { pembelajaran } & \text { inkuiri } \\
\text { dengan baik } & \end{array}$ & 12 \\
\hline Cukup & $61-75$ & $\begin{array}{l}\text { siswa dapat } \\
\text { mengikuti } \\
\text { pembelajaran inkuiri } \\
\text { dengan cukup baik }\end{array}$ & 13 \\
\hline Sedang & $51-60$ & $\begin{array}{l}\text { siswa kurang dapat } \\
\text { mengikuti } \\
\text { pembelajaran inkuiri }\end{array}$ & 2 \\
\hline Kurang & $\square \square 50$ & $\begin{array}{l}\text { siswa tidak dapat } \\
\text { mengikuti } \\
\text { pembelajaran inkuiri }\end{array}$ & $\mathbf{0}$ \\
\hline \multicolumn{3}{|r|}{ Jumlah } & 32 \\
\hline \multicolumn{3}{|c|}{ Rata-rata } & $78,52 \%$ \\
\hline \multicolumn{3}{|c|}{ Simpangan Baku } & 9,38 \\
\hline \multicolumn{4}{|c|}{$\begin{array}{l}\text { Kinerja Siswa: Berdasarkan hasil analisis deskriptif, } \\
\text { menunjukkan rata-rata kinerja sisiwa yang mengikuti } \\
\text { pembelajaran inkuiri based learning sebesar } 78,52 \% \text {, } \\
\text { berdasarkan kriteria kinerja pada instrument } \\
\text { menunjukkan bahwa siswa dapat mengikuti } \\
\text { pembelajaran inkuiri dengan baik. Dari hasil } \\
\text { pengamatan guru pengamat masih terdapat siswa yang } \\
\text { termasuk kedalam kriteria siswa kurang dapat } \\
\text { mengikuti pembelajaran inkuiri sebanyak } 2 \text { orang } \\
\text { siswa, ini menunjukkan bahwa diperlukan pembiasaan } \\
\text { siswa mengikuti pembelajaran inkuiri agar siswa lebih } \\
\text { terlibat langsung dalam proses memperoleh }\end{array}$} \\
\hline
\end{tabular}

Data kemampuan pemahaman konsep siswa diperoleh dari kegiatan yang dilakukan sebelum dan sesudah pembelajaran IBL dilakukan. Adapun hasil selengkapnya terdapat pada lampiran.

Tabel 5. Deskripsi Nilai test Pemahaman Konsep Siswa

\begin{tabular}{|c|c|c|c|}
\hline \multirow{2}{*}{ Nilai } & \multirow{2}{*}{ Kategori } & \multicolumn{2}{|c|}{ Frekuensi } \\
\hline & & Pretes & Postes \\
\hline $85-100$ & Tinggi Sekali & 0 & 1 \\
\hline $65-84$ & Tinggi & 0 & 23 \\
\hline $55-64$ & Cukup & 0 & 5 \\
\hline $35-54$ & Rendah & 10 & 3 \\
\hline $0-34$ & Rendah Sekali & 22 & 0 \\
\hline & Jumlah & 32 & 32 \\
\hline & Rata-rata & 30,13 & 70,88 \\
\hline & Terbesar & 44 & 96 \\
\hline & Terkecil & 20 & 48 \\
\hline & pangan Baku & 7,25 & 10,27 \\
\hline
\end{tabular}

Pemahaman Konsep siswa: Hasil analisis deskriptif diperoleh rata-rata pada pretest sebesar 30,13 dan pada postest sebesar 70,88 , hal ini menunjukkan bahwa setelah siswa mengikuti pembelajaran inkuiri, jeemahaman konsep siswa masuk pada kategori tinggi (65 - 84), sehingga dapat dikatakan bahwa dengan pembelajaran inkuiri pemahaman konsep siswa akan tinggi.

Peningkatan hasil belajar biologi peserta didik dengan normalisasi gane sebelum dan sesudah implementasi model pembelajaran inkuiri based learning (IBL)

Tabel 6. peningktan Hasil Belajar berdasarkan indeks Gain ternormalisasi

\begin{tabular}{|c|c|c|}
\hline Indeks Gain & Kategori & Frekuensi \\
\hline $0 \leq \mathrm{N}<0,3$ & Rendah & 0 \\
\hline $0,3 \leq \mathrm{N}<0,7$ & Sedang & 25 \\
\hline $0,7 \leq \mathrm{N} \leq 1,0$ & Tinggi & 7 \\
\hline Jumlah & 32 \\
\hline Rata-rata & 0,59 \\
\hline Terbesar & 0,93 \\
\hline \multicolumn{2}{|l|}{ Terkecil } & 0,32 \\
\hline \multicolumn{2}{|l|}{ Simpangan Baku } & 0,14 \\
\hline
\end{tabular}

Anaisis Gain Ternormalisasi: Peningkatan hasil elajar biologi peserta didik dengan normalisasi gane dan sesudah implementasi model sebesar 0,59 yang berarti bahwa terjadi peningkatan hasil belajar siswa setelah mengikuti pembelajaran inkuiri based learning pada kategori sedang

\section{KESIMPULAN}

Implementasi Model Pembelajaran Inkuiri Based Learning (IBL) pada pembelajaran biologi berpengaruh terhadap kinerja dan hasil belajar siswa. Peningkatan hasil belajar biologi siswa dengan normalisasi gane sebelum dan sesudah implementasi model pembelajaran inkuiri based learning terjadi peningkatan hasil belajar pada kategori sedang. 
1. Direktorat PSMA. 2014. Pembelajarn Biologi 3. Wenning, C.J. (2005a). Levels of inquiry: Melalui Pendekatan Saintifik. Jakarta: Kementrian Pendidikan dan Kebudayaan Direktorat Jenderal Pendidikan Menengah Direktorat Pembinaan Sekoan Menengah Atas.

2. Hake, R. 1999. Analyzing Change/Gain Scores. (Online),

(www.physics.indiana.edu/ sdi/AnalyzingChange -Gain.pdf)

\section{Hierarchies of pedagogical practices and inquiry} processes. Journal of Physics Teacher Education Online, 2(3), 3-11.

4. Wenning, C.J. (2010). Levels of inquiry: Using inquiry spectrum learning sequences to teach science. Journal of Physics Teacher Education Online, 5(4), 11-19. 